\title{
GLOBALIZAÇÃO E HUMANISMO INTEGRAL
}

\author{
GLOBALIZATION AND INTEGRAL HUMANISM
}

\section{Theodoro Vicente Agostinho ${ }^{1}$}

\author{
Antônio Márcio da Cunha Guimarães²
}

\begin{abstract}
Resumo: O presente trabalho tem como escopo demonstrar a conexão existente entre a globalização e o humanismo, essencialmente voltado para o humanismo integral, conceito estrito da palavra, onde garante a todos uma dignidade essencial sem qualquer distinção. Referido estudo enaltece a proteção a dignidade da pessoa humana tutelado na Constituição da República Federativa do Brasil de 1988, reforçando que o valor da vida humana é incomensurável, de modo que seu valor intrínseco não depende e não é acrescido por outra qualidade e, sua grandeza provém do fato unicamente de ser pessoa, digna de proteção e garantia do Estado para o progresso humanitário em conjunto com os avanços da globalização, visando à construção do bem comum.
\end{abstract}

Palavra-chave: Globalização - humanismo - humanismo Integral - dignidade da pessoa humana - progresso humanitário - construção do bem comum.

Abstract: The present work aims to demonstrate the connection between globalization and humanism, essentially focused on integral humanism, strict concept of the word, where it guarantees everyone an essential dignity without distinction. This study praises the protection of the dignity of the human person protected in the Constitution of the Federative Republic of Brazil of 1988, emphasizing that the value of human life is incommensurable so its intrinsic value does not depend and is not increased by another quality and, his greatness stems from the fact that he is only a person, worthy of state protection and guarantee for humanitarian progress in tandem with the advances of globalization, aiming at the construction of the common good.

Keywords: Globalization - humanism - humanism Integral - dignity of the human person humanitarian progress - construction of the common good.

\section{SUMÁRIO: INTRODRUÇÃO - 1. GLOBALIZAÇÃO - 1.1 CONCEITO - 1.2 ORIGEM DA GLOBALIZAÇÃO E SUAS CARACTERÍSTICAS - 2. HUMANISMO - 2.1 DEFINIÇÃO - 2.2 CARACTERÍSTICA DO HUMANISMO - 3. HUMANISMO}

\footnotetext{
${ }^{1}$ Doutorando e Mestre em Direito Previdenciário pela PUC/SP. Professor e Coordenador da Pós-Graduação em Direito Previdenciário da EBRADI. Ex-Conselheiro do CARF - Conselho Administrativo de Recursos Fiscais. Advogado. E-mail: professor.theodoro@terra.com.br

2 Doutor e Mestre em Direito Internacional pela PUC/SP; Professor da Faculdade de Direito da PUC/SP desde 1991 (Bacharelado/Mestrado/Doutorado); Visiting Professor/Researcher on King's College University of London; Visiting Professor/Researcher na Università Degli Studi di Milano; Advogado e consultor jurídico desde 1986 - OAB/SP: 82.984; Lider do Grupo de Pesquisa da PUC/SP junto ao CNPq - DIGE - Direito Internacional e Globalização Econômica; Autor de obras jurídicas.
} 


\section{INTEGRAL - 3.1 CONCEITO - 3.2 POSITIVISMO - HUMANISMO SOCIALISTA - HUMANISMO INTEGRAL - 3.3 PROTEÇÃO CONSTITUCIONAL - 3.4 BEM COMUM - 4. CONCLUSÃO - REFERÊNCIAS BIBLIOGRÁFICAS.}

\section{INTRODUÇÃO}

Tanto a origem da globalização quanto a origem do humanismo remontam ao século XV D.C. durante o período mercantilista, de modo que várias nações europeias lançaram-se ao mar em busca de novas terras e riquezas em prol de subsistência e melhores condições de vida.

O humanismo por sua vez decorreu do movimento intelectual iniciado na Itália com o Renascimento, rompendo forte influência da Igreja e do pensamento religioso da Idade Média, de modo a tal que o teocentrismo cede lugar ao antropocentrismo, passando o homem a ser o centro de interesse.

Nada obstante, o humanismo significa valorizar o ser humano e a condição humana acima de tudo, relacionando-se, pois, com a generosidade, compaixão e preocupação em valorizar os atributos e realizações humanas.

Sua importância para com a história da humanidade fora justamente à transição entre a idade Média e a Idade Moderna, cujo movimento revolucionou o campo cultural e ainda ofereceu novas formas de reflexão sobre as artes, ciências e a própria política social.

A ideia do Humanismo Integral foi criada por Jacques Maritain, filósofo francês de orientação católica, influenciador direto no conceito de Democracia Cristã $\tilde{a}^{3}$, sendo que em 1936 publicou a obra relacionada ao Humanismo Integral (Humanisme intégral, 1936).

Para Jacques Maritain, no Humanismo Integral o homem é concebido à imagem e semelhança de Deus, o que lhe garante uma dignidade humana especial, ou seja, é uma pessoa humana.

Complementa, ainda, que a infelicidade do humanismo clássico foi de ter sido antropocêntrico e não ter sido humanismo, esquecendo que na ordem do ser e do bem, Deus é que possui a primeira iniciativa e que vivifica a liberdade do homem, ensejando em uma época dualista, afastando-se do conceito vital.

\footnotetext{
3 Pensamento, ideologia e movimento político que defende uma democracia baseada nos ensinamentos e princípios cristãos, tais como a liberdade, a solidariedade e a justiça. Ela é democrática na medida em que desde a sua origem, aderiu aos ideais da democracia pluralista do tipo ocidental. E é cristã porque representa uma tentativa permanente de defesa e aplicação dos princípios e valores cristãos na vida política nacional e internacional.
} 
Devemo-nos observar que a ideia central do Humanismo Integral persiste nos dias atuais, inclusive, com proteção do Estado elencado em nossa Carta Magna, precisamente, no art. $5^{\circ}$ da Constituição da República Federativa do Brasil de 1988, que trata, dentre suas previsões, do valor absoluto da dignidade da pessoa humana na qualidade de princípio fundamental.

$\mathrm{Na}$ realidade, várias são as passagens na Constituição Federal que denotam a dignidade da pessoa humana, de toda maneira, tem sua fonte ética na dignidade da pessoa humana os direitos, liberdades, garantias pessoais, direitos econômicos, sociais, culturais a toda a pessoa.

Frisa-se, que o objetivo do presente trabalho é demonstrar a conexão existente entre a globalização e o humanismo integral, onde garante a todos uma dignidade essencial sem qualquer distinção, visando o progresso da humanidade com a construção do bem comum.

Há de ser ressaltado, também, alguns pontos sobre a proteção estatal, em especial, se está sendo corretamente prestado os serviços sociais sob a ótica do Humanismo Integral, de igual modo, se a globalização é um fenômeno que auxilia ou que deveria auxiliar para a correta implementação do Humanismo Integral.

Inobstante, o objetivo último de todas as ações que acontecem na vida social é a construção do bem comum, que coincide com a plena realização de cada pessoa em prol do progresso e do avanço da humanidade, pautado pela ética e pelo senso comum e de justiça, cabendo ao Estado garantir a possibilidade de realização de ações sociais de cada indivíduo, assim como delimite nossa Constituição.

De outro lado, temos a meteórica evolução da tecnologia, mormente nos transportes e nas comunicações, que impulsionaram de forma assustadora o fenômeno da globalização. Embora seja um movimento antigo, de expansão da humanidade, que inquieta, sempre busca conhecer novos horizontes, explorar terras desconhecidas, conquistar mercados distantes e expandir o comércio, nos últimos séculos (XX e atual XXI) seu desenvolvimento foi realmente impressionante.

O homem passa a se relacionar com outros semelhantes, que estão localizados do outro lado do planeta, de forma instantânea - online - real time - nós somos hoje capazes de falar e ver outras pessoas na mesmo segundo, e com isso saber o que está acontecendo em outros lugares, distantes, e mais, interagir com eles.

Essa comunicação imediata, aliada à facilidade de transporte - mais rápidos e mais seguros, está praticamente remodelando o mundo que conhecíamos anteriormente. Uma 
dúvida se impõe - será que os Governos Estatais terão ainda a influência e poder de outrora? sobre os seus cidadãos?

Aliando os dois temas, é possível imaginar, de uma forma otimista, que o homem passará a ter, não mais e mais direitos, mas sim, o reconhecimento e a proteção de seus direitos (já existentes, eternos e imutáveis - direito natural), em razão dessa extrema vigilância hoje possibilitada pela globalização.

\section{GLOBALIZAÇÃ̃}

\subsection{CONCEITO}

A Globalização consiste, em síntese, num processo de aprofundamento das relações econômicas, sociais, culturais e políticas entre os povos distintos, caracterizada de certa maneira pela ausência ou diminuição de barreiras econômicas e imigratórias entre diferentes países.

Embora tenha inúmeras abordagens para a definição de Globalização, vale a pena destacar alguns aspectos em comum, quais sejam: processo à escala mundial, ou seja, transversal ao conjunto dos Estados-Nação que compõem o mundo; desenvolvimentos tecnológicos que facilitam a comunicação entre pessoas e entre instituições e que facilitam a circulação de pessoas, bens e serviços, constituem um importante centro nevrálgico da Globalização.

Para HELD, Globalização ${ }^{4}$ é "uma força condutora central por trás das rápidas mudanças sociais, políticas e econômicas que estão a remodelar as sociedades modernas e a ordem mundial.".

Já para WATERS", a "Globalização pode definir-se como um processo social através do qual diminuem os constrangimentos geográficos sobre os processos sociais e culturais, e em que os indivíduos se consciencializam cada vez mais dessa”.

Por fim, STIGLIZ" defende que "Fundamentalmente, é a integração mais estreita dos países e dos povos que resultou da enorme redução dos custos de transportes e de comunicação e a destruição de barreiras artificiais à circulação transfronteiriça de mercadorias, serviços, capitais, conhecimentos e (em menor escala) pessoas".

\footnotetext{
${ }^{4}$ HELD, David, Anthony Mcgrew (et al) (1999), Global Transformations: Politics, Economics and Culture, Cambridge, Polity Press.

5 WATERS, Malcom (1999), Globalização, Oeiras, Celta.

${ }^{6}$ STIGLITZ, Joseph E. (2004), Globalização: a Grande Desilusão, Lisboa, Terramar.
} 
De toda maneira, pode-se concluir que Globalização é o processo de aproximação entre as diversas sociedades e nações existentes por todo o mundo, seja no âmbito econômico, social, cultural ou político.

\subsection{ORIGEM DA GLOBALIZAÇÃO E SUAS CARACTERÍSTICAS}

A origem da Globalização remonta ao século XV durante o período mercantilista, onde várias nações europeias lançaram-se ao mar em busca de novas terras e riquezas. Assim, o europeu entrou em contato com povos de outros continentes, estabelecendo fortes relações comerciais e culturais.

No século XIX, já com a invenção da eletricidade, ferrovias e dos navios à vapor, a globalização intensificou ante a agilidade e facilidade na aquisição e venda de produtos interestaduais e intercontinentais.

Desde o início da globalização, até fatores marcantes na história da humanidade como a primeira e segunda guerra mundial, fim da União Soviética, surgimento do neoliberalismo, fez como que o processo de globalização fosse impulsionado pelos quatro cantos do mundo.

Inclusive, diante de tais fatos e, com intuito de construir um mundo sob novos alicerces ideológicos, os dirigentes das nações que emergiam como potências pós guerra, estabeleceram na Conferência de Yalta na Rússia, em 1945, as bases de uma futura paz mundial, com o fito de evitar guerras e promover a paz, a democracia e fortalecer os Direito Humanos, fora esboçado a declaração universal dos Diretos Humanos (DUDH), adotado efetivamente pela Organização das Nações Unidas em 10 de dezembro de 1948.

Posteriormente, ante inúmeras convenções e recomendações internacionais, fora criada a Organização Internacional do Trabalho (OIT), voltada, especialmente, para o cumprimento das normas internacionais, tendo, pois, como missão o desenvolvimento de oportunidades para que homens e mulheres pudessem ter acessos ao trabalho decente e produtivo, respeitando as condições mínimas ao ser que o Estado deve tutelar, como liberdade, equidade, segurança e dignidade humana.

Nota-se que o princípio da constituição da DUH como da OIT, decorre da base do Humanismo, tanto que o propósito mor que ampara referidos conceitos é de que "todos os seres humanos, independentemente da raça, credo ou sexo, têm direito a prosseguir o seu progresso material e o seu desenvolvimento espiritual na liberdade e na dignidade, na 
segurança econômica e com oportunidades iguais”. (Declaração das Nações Unidas Direito ao Desenvolvimento, Organização das Nações Unidas, de 9 de dezembro de 1975).

Podem-se destacar, como características gerais da globalização, os seguintes aspectos: Integração social, econômica e política entre povos de diferentes países; união do mercado mundial; fortalecimento das relações internacionais; avanço tecnológico e dos meios de comunicação; aumento de concorrência econômica e do nível de competição; surgimento dos blocos econômicos; crescimento da economia; dentre outros.

\section{HUMANISMO}

\subsection{DEFINIÇÃO}

Em sentido amplo, humanismo significa valorizar o ser humano e a condição humana sobre tudo, relacionado, pois, com generosidade, compaixão e preocupação em valorizar os atributos e realizações humanas.

O humanismo foi um movimento intelectual iniciado na Itália no século XV com o Renascimento, rompendo neste momento a forte influência da Igreja e do pensamento religioso da Idade Média.

Com o surgimento do Humanismo o teocentrismo, cuja crença consistia em Deus como centro de tudo, cedeu lugar ao Antropocentrismo, ou seja, passou o homem a ser o centro de interesse.

MARITAIN $^{7}$, em sua obra Humanismo Integral, defende que

“(...) o humanismo (e uma tal definição pode ser desenvolvida segundo linhas muito divergentes) tende essencialmente a tornar o homem mais verdadeiramente humano, e a manifestar sua grandeza original fazendo-o participar de tudo o que o pode enriquecer na natureza histórica ("concentrando o mundo no homem", como dizia mais ou menos Seheler, e "dilatando o homem ao mundo).

Entendia, ainda, que o humanismo era inseparável da civilização ou da cultura, tornando-as sinônimas para a finalidade do humanismo.

Em resumo, o humanismo procurou obter o melhor dos seres humanos, afastando-se do absolutismo da religião, oferecendo, assim, novas formas de reflexão sobre as artes, ciências e a política, sendo que, especificamente, no ramo da ciência, o pensamento humanista

\footnotetext{
${ }^{7}$ MARITAIN, Jacques. Humanismo Integral. Uma visão nova da ordem cristã. Editora Nacional.1941.
} 
resultou no afastamento dos dogmas da igreja e proporcionou grandes progressos em ramos como a física, matemática, engenheira e medicina.

\subsection{CARACTERÍSTICA DO HUMANISMO}

Dentre as principais características do humanismo, destacam-se o período de transição entre a idade Média e o Renascimento; valorização do ser humano; surgimento da burguesia; valorização dos artistas ante as emoções humanas; afastamento dos dogmas da religião; valorização de debates e opiniões divergentes; valorização do racionalismo e o método científico.

Pode-se, ainda, subdividir o conceito principal do humanismo em três vertentes, quais sejam:

Primeiro a ideia do ser humano no centro do universo (antropocentrismos), onde o ser humano passou a ocupar o centro de interesses da sociedade, das artes e das ciências. Com isso, o ser humano tomou o lugar que antes era ocupado incessantemente pela religião, isto é pelo poder centralizado da igreja.

Segundo o retorno aos estudos sobre o mundo clássico, na verdade os renascentistas passaram a idealizar uma cultura greco-romana como perfeita e, por isso, motivou a copiá-la, no sentindo de que a razão deveria subsistir para o progresso social.

Terceiro a racionalidade acima da superstição, onde houve vasto abandono às explicações supersticiosas ou baseadas somente na fé, os questionamentos passaram a ter uma explicação racional, ou seja, baseada na razão e comprovável cientificamente, por isso, inclusive, houve o incentivo às ciências.

\section{HUMANISMO INTEGRAL}

\subsection{CONCEITO}

O conceito de humanismo integral foi criado por MARITAIN, como mencionado inicialmente, foi um filósofo francês de orientação católica, influenciador direto no conceito de Democracia Cristã, sendo que em 1936 publicou a obra relacionada ao Humanismo Integral (Humanisme intégral, 1936). 
Para MARITAIN, no Humanismo Integral, o homem é concebido à imagem e semelhança de Deus, o que lhe garante uma dignidade humana especial, ou seja, é uma pessoa humana.

O Humanismo de MARITAIN (1941, p.2) exige, essencialmente, a preservação e a garantia da dignidade da pessoa humana no plano de uma ação prática, igualmente nos direitos do homem e no ideal de liberdade, igualdade e fraternidade Cabe ressaltar que ao proteger os direitos da pessoa, não há pretensão de idolatrá-lo como um ser acima dos outros seres da natureza. $\mathrm{Na}$ realidade, MARITAIN contesta expressamente o humanismo antropocêntrico individualista e burguês, na qual colocou o homem no centro as coisas. Deste modo afirma:

A palavra humanismo é um vocábulo ambíguo. É claro que aquele que o pronuncia compromete de logo uma metafísica, e que, segundo existe ou não no homem alguma coisa que respira acima do tempo, e uma personalidade cujas necessidades mais profundas ultrapassam toda ordem do universo, a Idea que se fará do humanismo terá ressonâncias inteiramente diferente. (...) Devemos ser advertidos em qualquer caso em não definir o humanismo pela exclusão de toda ordenação ao super-humano e pela abjuração de toda transcendência (MARITAIN, 1941, p.2).

O conceito também fora explanado pelo papado onde o Papa Paulo VI afirmou que com a encíclica Populorum Progressio ${ }^{8}$ foi ponto central da doutrina social da Igreja; o Papa João Paulo II em reiteradas ocasiões se referiu à necessidade de se promoverem os valores de um humanismo integral consolidando com a encíclica Sollicitudo Rei Socialis ${ }^{9}$; o Papa Bento XVI retorna ao conceito de humanismo integral ao falar no desenvolvimento humano integral, na encíclica Caritas in Veritate ${ }^{10}$ de 2009; por fim o Papa Francisco criou o Dicastério ${ }^{11}$ para o Serviço do Desenvolvimento Humano Integral.

No intuito de contextualizar, Doutrina Social da Igreja (DSI) é considerada o conjunto dos ensinamentos contidos na doutrina da Igreja Católica e no Magistério da Igreja Católica, constante de numerosas encíclicas e pronunciamentos dos papas inseridos na tradição multissecular, e que tem suas origens nos primórdios do cristianismo.

Tem por finalidade fixar princípios, critérios e diretrizes gerais a respeito da organização social e política dos povos e das nações. É um convite a ação. A finalidade da

\footnotetext{
${ }^{8}$ Populorum progressio é uma famosa encíclica escrita pelo Papa Paulo VI e publicada em 26 de março de 1967. A encíclica é dedicada à cooperação entre os povos e ao problema dos países em desenvolvimento.

${ }^{9}$ Sollicitudo rei socialis é uma encíclica promulgada pelo Papa João Paulo II em 30 de dezembro de 1987, no vigésimo aniversário da Populorum progressio.

${ }^{10}$ Caritas in Veritate é o título da terceira encíclica do Papa Bento XVI. Datado de 29 de junho de 2009, foi finalmente publicado no dia 7 de Julho de 2009.

${ }^{11}$ Dicastério é o nome para os departamentos do governo da Igreja Católica que compõem a Cúria Romana. Entre os dicastérios estão: a Secretaria de Estado, as congregações, os tribunais eclesiásticos, conselhos, ofícios, comissões e comités. O Papa delega a cada dicastério uma função do governo.
} 
doutrina social da Igreja, como dito no Vaticano em 2004, é de "levar os homens a corresponderem, com o auxílio também da reflexão racional e das ciências humanas, à sua vocação de construtores responsáveis da sociedade terrena".

Possível identificar, portanto, a aplicação da proposta de MARITAIN que consistia no ideal do Humanismo Integral ou da denominada "Nova Cristandade".

Para os Professores Wagner Balera e Ricardo Sayeg ${ }^{12}$ o Humanismo Integral trata-se do mapa que decifra o Direito Natural da fraternidade em favor do homem todo e de todos os homens, bem como do planeta (BALERA e SAYEG, 2011, p.86).

Aliás, vale ressaltar que o Humanismo Integral traz a ideia de solidariedade na fraternidade, elemento este de união entre ela própria, liberdade e a igualdade.

Esse ideal está consagrado no Artigo $1^{\circ}$ da Declaração Universal de Direitos Humanos:

"Art. I. Todas as pessoas nascem livres e iguais em dignidade e direitos. São dotadas de razão e consciência e devem agir em relação umas às outras com espírito de fraternidade".

Embora a Declaração Universal de Direitos Humanos não seja um documento com obrigatoriedade legal, serviu como base para os dois tratados sobre direitos humanos da ONU de força legal: o Pacto Internacional dos Direitos Civis e Políticos e o Pacto Internacional sobre os Direitos Econômicos, Sociais e Culturais. As ideias e valores dos direitos humanos podem ser traçadas através da história antiga e das crenças religiosas e culturais ao redor do mundo.

No Humanismo de MARITAIN, o que depreendemos é que a dignidade não é atribuída à pessoa, apenas no seu individualismo, mas inserida na sua vocação de ser social, para encarnar-se no ideal de uma sociedade fraterna e solidária.

Para ele a obra da cidade seria realizar uma vida comum terrena, um regime temporal verdadeiramente conforme a esta dignidade, a esta vocação e a este amor (MARITAIN, 1941, p.195).

Assim, em apertada síntese, chega-se à conclusão de que buscar o bem comum é a tarefa fundamental do Estado, mas isto só poderá ser realizado com a colaboração de todas as pessoas.

No raciocínio de MARITAIN, para o Humanismo Integral, "A questão é dar a cada pessoa humana a possibilidade real e concreta de aceder (sob modos que podem ademais

\footnotetext{
${ }^{12}$ SAYEG, Ricardo; BALERA, Wagner. O Capitalismo Humanista. Petrópolis: Editora KBR, 2011.
} 
variar muito, e que não excluem, quando são necessárias, certas coletivizações), às vantagens da propriedade privada dos bens terrestres." (MARITAIN, 1941, p. 178)

Vale dizer que no Humanismo Integral enaltece a ética, como sendo o fundamento de qualquer processo transformador da vida pessoal e social, busca-se, com um isso um progresso moral individual para com a sociedade (progresso humanitário).

Conquanto, o Estado não deve ser o grande protagonista das ações na vida social e na construção do bem comum. Este protagonismo cabe às pessoas e suas organizações, de modo que o Estado deve garantir a possibilidade de realizações destas ações, agindo subsidiariamente.

\subsection{POSITIVISMO - HUMANISMO SOCIALISTA - HUMANISMO INTEGRAL}

Ainda em relação ao Humanismo integral, bom de se acrescentar um pouco mais acerca da vida e obra de MARITAIN, que viveu numa época em que o positivismo encontrava forte aceitação e o liberalismo defendia a ideia de um mundo livre, mas independente do respeito ao ser humano. A obra e pensamento de MARITAIN vem de encontro a esses fundamentos, na medida em que escreve sobre uma sociedade no qual o mais importante é o Bem Comum, de vez que este propicia uma vida melhor para todos os homens.

Baseado na teoria tomista, ele tenta resgatar o conceito e importância da dignidade do ser humano e sua liberdade, devendo os dois princípios coexistirem. Como já exposto em um outro artigo - de lavra de Antônio Márcio da Cunha Guimarães e Adriano Stagni Guimarães, para Maritain: "a ética deve estar subordinada à teologia, propondo ainda, um humanismo integral, no qual o homem possui dois aspectos a serem considerados - a sua individualidade - material, e o seu lado pessoal - espiritual." ${ }^{\prime 13}$

A crítica maior que MARITAIN faz ao Humanismo Socialista, ou melhor Humanismo Marxista - em sua obra Humanismo Integral, é a completa ausência de Deus. No seu entendimento, a crença em Deus é parte fundamental da existência humana e não pode ser negligenciada e muito menos, excluída. Ao propor a teoria do humanismo integral, visualiza o homem vivendo e convivendo em sociedade, mas sob princípios cristãos, ainda que o Estado seja laico.

13 GUIMARÃES, Antonio Marcio da Cunha; GUIMARÃES, Adriano Stagni. O papel da Igreja na sociedade, colaborando com um Estado laico. In: SANTOS, Ivanaldo; POZZOLI, Lafayette. (Org.). Direitos Humanos e Fundamentais e Doutrina Social. 1 ed. Birigui/SP: Boreal, 2012, v. 1, p. 165-175. 
Contudo, na proposta de MARITAIN, o "humanismo integral não pretende impor às pessoas a fraternidade pela via da convicção religiosa", pois não é função da comunidade política direcionar a pessoa no seu caminho espiritual. Qualquer um pode escolher livremente o credo que desejar, inclusive a instituição do Estado laico é justamente o reconhecimento e tolerância de todos os credos.

O cristianismo em si, exerceu uma forte influência no Direito Ocidental porque os ensinamentos de Jesus Cristo tiveram grande influência na reforma do humanismo clássico da Renascença.

Direito esse, que por ser um objeto cultural, sofre influências da tradição social e religiosa dos povos que o criou, absorvendo os valores vigentes da fraternidade e caridade da doutrina Cristã, e que ensejaram a evolução de uma doutrina inclusiva dos Direitos Humanos.

Com isso, não são os dogmas específicos que moldam a experiência jurídica, que sequer precisa ser encarada religiosamente, uma vez que "vemos o cristianismo como um bem cultural que aceita submeter-se ao olhar antropológico", mas a consciência histórica dos países ocidentais que lograram êxito em promover, economicamente e politicamente, suas leis.

\subsection{PROTEÇÃO CONSTITUCIONAL}

Como relatado anteriormente, o Estado deve garantir a possibilidade ao homem para a realização de suas ações tanto na vida social quanto na construção do bem comum, sendo esta a ideia correlacionada à proteção do Estado prevista na Carta Magna.

Trata-se, pois, do valor absoluto da dignidade da pessoa humana na qualidade de princípio fundamental e sua possibilidade de relativização. Segundo Carlos Alberto Siqueira ${ }^{14}$ "têm a sua fonte ética na dignidade da pessoa humana os direitos, liberdades e garantias pessoais e os direitos econômicos, sociais e culturais comuns a todas as pessoas" (MIRANDA apud SIQUEIRA CASTRO, p.174)

No preâmbulo da Constituição Federativa do Brasil de 1988, inclusive, é possível identificar a ideia de fraternidade relacionada diretamente no reconhecimento constitucional, senão vejamos:

PREÂMBULO

\footnotetext{
${ }^{14}$ CASTRO, Carlos Roberto Siqueira. Dignidade da Pessoa Humana: o princípio dos princípios constitucionais: in SARMENTO, Daniel. GALDINO, Flávio (Org). Direitos Fundamentais: Estudos em homenagem ao professor Ricardo Lobo Torres. Rio de Janeiro: Renovar, 2006. p.135-179.
} 
Nós, representantes do povo brasileiro, reunidos em Assembléia Nacional Constituinte para instituir um Estado Democrático, destinado a assegurar o exercício dos direitos sociais e individuais, a liberdade, a segurança, o bem-estar, o desenvolvimento, a igualdade e a justiça como valores supremos de uma sociedade fraterna, pluralista e sem preconceitos, fundada na harmonia social e comprometida, na ordem interna e internacional, com a solução pacífica das controvérsias, promulgamos, sob a proteção de Deus, a seguinte CONSTITUIÇÃO DA REPÚBLICA FEDERATIVA DO BRASIL.

Referida concepção já era ressaltada por MARITAIN que afirmava que "somos nascidos para tender à perfeição do amor, de um amor que envolve realmente a universalidade dos homens, sem deixar lugar para o ódio contra nenhum deles, e que transforma realmente nosso ser". (MARITAIN, 1941, p.88)

Cabe ressaltar que várias são as passagens na Constituição Federal que denotam a dignidade da pessoa humana, como no artigo $5^{\circ}$, incisos III (não submissão a tortura), VI (inviolabilidade da liberdade de consciência e de crença), VIII (não privação de direitos por motivo de crença ou convicção), X ( inviolabilidade da vida privada, honra e imagem), XI (inviolabilidade de domicílio), XII (inviolabilidade do sigilo de correspondência), XLVII (vedação de penas indignas), XLIX (proteção da integridade do preso), dentre outros.

A dignidade da pessoa humana é fundada, pois, sobre aquilo que ela é enquanto tal. Deste modo o valor da vida humana ou da pessoa humana é incomensurável: o seu valor intrínseco não depende e não é acrescido por outra qualidade. De fato, toda a grandeza do homem lhe provém do fato de ser pessoa.

Temos por dignidade da pessoa humana a qualidade intrínseca e distintiva de cada ser humano que o faz merecedor do mesmo respeito e consideração por parte do Estado e da comunidade, implicando, neste sentido, um complexo de direitos e deveres fundamentais que assegurem a pessoa tanto contra todo e qualquer ato de cunho degradante e desumano, como venham a lhe garantir as condições existenciais mínimas para uma vida saudável, além de propiciar e promover sua participação ativa corresponsável nos destinos da própria existência e da vida em comunhão dos demais seres humanos.

$\mathrm{O}$ entendimento atual da dignidade da pessoa humana possui origens religiosas e filosóficas segundo o Professor e Ministro do STF Barroso"15, conceitua: "A dignidade humana, como atualmente compreendida, se assenta sobre o pressuposto de que cada ser humano possui um valor intrínseco e desfruta de uma posição especial no universo". (BARROSO, 2014, p.14)

15 BARROSO, Luís Roberto. A dignidade da pessoa humana no direito constitucional contemporâneo: a construção de um conceito jurídico à luz da jurisprudência mundial. Tradução Humberto Laport de Mello. Belo Horizonte: Fórum, 2014, p. 14. 
Portanto, sendo a dignidade da pessoa humana um fundamento da República, a essa categoria erigido por ser um valor central do direito ocidental que preserva a liberdade individual e a personalidade, portanto, um princípio fundamental alicerce de todo o ordenamento jurídico pátrio, não há como ser mitigado ou relativizado, sob pena de gerar a instabilidade do regime democrático, o que confere ao dito fundamento caráter absoluto.

Nesse sentido, PIOVESAN ${ }^{16}$ diz que a dignidade da pessoa humana: "está erigida como princípio matriz da Constituição, imprimindo-lhe unidade de sentido, condicionando a interpretação das suas normas e revelando-se, ao lado dos Direitos e Garantias Fundamentais, como cânone constitucional que incorpora "as exigências de justiça e dos valores éticos, conferindo suporte axiológico a todo o sistema jurídico brasileiro."

Ainda nesse contexto de conferir à dignidade da pessoa humana um status de princípio fundamental, essencial, fonte de todo ordenamento jurídico brasileiro.

Logo, a dignidade da pessoa humana, se tomada como fundamento da República, princípio fundamental do ordenamento pátrio, mínimo de direitos que garantem uma existência digna a todos, não pode ser relativizada por constituir valor absoluto, vez que, nessa hipótese, o indivíduo é protegido por ser colocado em contraposição à sociedade ou ao Poder Público, portanto, em situação de vulnerabilidade.

\subsection{BEM COMUM}

A ideia do bem comum no remete a reflexão de vários conceitos filosóficos, teólogos, sociólogos, no sentido de ser um conjunto de benefícios compartilhados por todos os membros ou, por sua maioria, de uma dada comunidade ou população.

A doutrina social da Igreja formulou o seu conceito na encíclita Pacem in Terris ${ }^{17}$ onde considerava o bem comum como sendo um conjunto de todas as condições de vida social que favoreçam o desenvolvimento integral da personalidade humana e na sociedade em que habita.

Por outras palavras, o bem comum é o fim das pessoas singulares que existem na comunidade, ou seja, o bem da comunidade é o bem ou propósito do próprio indivíduo que a compõe o que remete a reflexão de MARITAIN a respeito do Humanismo Integral.

\footnotetext{
${ }^{16}$ PIOVESAN, Flávia. Direitos humanos e o direito constitucional internacional. 4ed. São Paulo: Max Limonad, 2000.

17 Carta-Encíclica do Papa João XXIII sobre "a Paz de todos os povos na base da Verdade, Justiça, Caridade e Liberdade". Foi publicada no dia 11 de Abril de 1963
} 
Aliás, nessa relação entre Estado e o bem comum, MARITAIN afirmava que: “A obra da cidade seria realizar uma vida comum terrena, um regime temporal verdadeiramente conforme a esta dignidade, a esta vocação e a este amor." (MARITAIN, 1941, p.195)

O bem comum, por vezes, tem sido visto como uma utilitária ideal, o que representa o maior bem possível para o maior número possível de pessoas.

Outra definição do bem comum, como o objetivo por excelência do Estado, requer uma admissão de direito fundamental do indivíduo na sociedade, ou seja, o direito de todos à oportunidade de livremente moldar sua vida por ação responsável, em busca de virtude e de acordo com a lei moral.

Cabe destacar que o grau e forma do poder político, no exercício da governação, devese remeter a preservação da comunidade e a liberdade dos seus membros. Isso acontece porque todo indivíduo é dotado de livre arbítrio e só está disposto a sacrificar parte da sua liberdade se esse sacrifício se traduzir em benefício da comunidade na qual está inserido, ou se isto servir para garantir a sua própria subsistência.

$\mathrm{Na}$ ideia essencialmente filosófica o bem comum está relacionado com o ideal de progresso que todas as sociedades devem alcançar, quais sejam: a igualdade social, econômica, oportunizando a todos melhores condições de vida.

Inclusive, a partir de estudos filosóficos sobre o conceito do bem comum, a justiça brasileira determina o bem comum como algo que agrada a todos, ao povo, a comunidade, inclusive, de modo que as leis devem ser feitas para um Estado coletivo e não individual.

\section{CONCLUSÃO}

Após essa breve análise do pensamento de MARITAIN e também dos efeitos da Globalização, podemos concluir o primado da pessoa sobre as coisas e sobre os processos sociais. De forma a tal que o bem comum não se confunde com uma situação de equilíbrio entre os interesses individuais nem pode ser construído em oposição ao bem pessoal.

Afinal, a pessoa é uma totalidade que não pode ser reduzida às suas várias dimensões (econômica, cultural, social, etc.).

O objetivo último de todas as ações que acontecem na vida social é a construção do bem comum, que coincide com a plena realização de cada pessoa, de forma integral 
A dimensão ética, enquanto manifestação da liberdade da pessoa está presente em todas as esferas da vida (pessoal, econômica, política, etc.) e é necessária para a construção do bem comum.

Portanto, não se pode pensar em progresso, desenvolvimento ou justiça social sem uma atenção particular para com a ética pessoal.

Sendo certo que o Estado não deve ser o grande protagonista das ações na vida social e na construção do bem comum, este protagonismo cabe às pessoas e suas organizações. Ao Estado cabe garantir a possibilidade de realização destas ações, numa postura subsidiária, respeitando, pois, os ditames constitucionais, especialmente, voltados à dignidade da pessoa humana.

Mesmo que possam restar caracterizados os problemas no processo de desenvolvimento socioeconômico e político das nações, em especial, do Brasil, sendo justamente como consequências da falta de uma perspectiva integral de pessoa e do desenvolvimento, necessitamos refletir sobre a adequada relação e proteção do Estado e Sociedade.

Não podemos deixar expandir a ideia de uma falsa polarização entre um Estado liberal desvinculado dos interesses do bem comum e um Estado social no qual todos os serviços públicos e toda a vida social estão submetidas ao governo. De modo a tal que a pessoas devem fazer jus a seus direitos e vindicá-los para a devida chancela do Estado.

A globalização, por seu turno é um fenômeno que tende a acompanhar o desenvolvimento da sociedade, todavia, de forma exponencial, de modo que não deixa dúvida quanto à sua relação com o Humanismo.

Nada obstante, para que haja o progresso humanitário, o avanço social, há de ser modificada inicialmente a personalidade de cada ser humano, pautado na ética e na moral, a fim de cobrar efetivamente a proteção do Estado, especialmente, ao mínimo social e as garantias fundamentais a pessoa humana, caminhando, somente assim, ao ideal de uma sociedade juta, fraterna e solidária. 


\section{REFERÊNCIAS BIBLIOGRÁFICAS}

BARROSO, Luís Roberto. A dignidade da pessoa humana no direito constitucional contemporâneo: a construção de um conceito jurídico à luz da jurisprudência mundial. Belo Horizonte: Fórum, 2014, p. 14.

PIOVESAN, Flávia. Direitos Humanos e o Direito Constitucional Internacional. $4^{\mathrm{a}}$ ed. São Paulo: Max Limonad, 2000.

BENTO XVI. Caritas in veritate. 29 de junho de 2009. Disponível em: http://w2.vatican.va/content/benedict-xvi/pt/encyclicals/documents/hf_benxvi_enc_20090629_caritas-in-veritate.html. Acesso em: 14 de mai. 2018.

CASTRO, Carlos Roberto Siqueira. Dignidade da Pessoa Humana: o princípio dos princípios constitucionais. In SARMENTO, Daniel. GALDINO, Flávio (Org). Direitos Fundamentais: Estudos em homenagem ao professor Ricardo Lobo Torres. Rio de Janeiro: Renovar, 2006. p.135-179.

BRASIL. Constituição da República Federativa do Brasil de 1988. Disponível em: http://www.planalto.gov.br/ccivil_03/constituicao/constituicaocompilado.htm. Acesso em: 14 mai. 2018.

Senado Federal. Direitos Humanos Direitos Humanos atos internacionais e

normas correlatas. 31 de agosto de 2013. Disponível em: http://www2.senado.leg.br/bdsf/bitstream/handle/id/508144/000992124.pdf? sequence=1.

Acesso em: 14 de mai. 2018.

GUIMARÃES, Antonio Marcio da Cunha; GUIMARÃES, Adriano Stagni. O papel da Igreja na sociedade, colaborando com um Estado laico. In: SANTOS, Ivanaldo; POZZOLI, Lafayette. (Org.). Direitos Humanos e Fundamentais e Doutrina Social. $1^{\mathrm{a}}$ ed. Birigui/SP: Boreal, 2012, v. 1, p. 165-175.

HELD, David, Anthony Mcgrew (et al) (1999). Global Transformations: Politics, Economics and Culture. Cambridge, Polity Press.

JOÃO PAULO II. Sollicitudo Rei Socialis. 30 de dezembro de 1987. Disponível em: http://w2.vatican.va/content/john-paul-ii/pt/encyclicals/documents/hf_jp-

ii_enc_30121987_sollicitudo-rei-socialis.html. Acesso em: 14 mai. 2018.

MARITAIN, Jacques. Humanismo Integral. Uma visão nova da ordem cristã. Editora Nacional.1941.

Humanismo integral. Tradução de Afranio Coutinho, Rio de Janeiro: Cia. Editora Nacional, 1945. p. 85 e seguintes.

MOYN, Samuel. Jacques Maritain, Christian New Order, and the Birth of Human Rights. Columbia University Academic Commons, 2008. p. 4 
PAULO VI. Populorum progressio. 26 de março de 1967. Disponível em: http://w2.vatican.va/content/paul-vi/pt/encyclicals/documents/hf_p-

vi_enc_26031967_populorum.html. Acesso em: 14 de maio. 2018.

SAYEG, Ricardo; BALERA, Wagner. O Capitalismo Humanista. Petrópolis: Editora KBR, 2011.

STIGLITZ, Joseph E.. Globalização: a Grande Desilusão. Lisboa: Terramar, 2004.

STO. TOMÁS DE AQUINO. Sto. Tomás de Aquino - vida e obra. Bauru: Nova Cultura, 1996.

VATICANO. Compêndio da Doutrina Social da Igreja. 29 de junho de 2004. Disponível em:

http://www.vatican.va/roman_curia/pontifical_councils/justpeace/documents/rc_pc_justpeace _doc_20060526_compendio-dott-soc_po.html\#SECRETARIA\%20DE\%20ESTADO. Acesso em: 14 mai. 2018.

WATERS, Malcom. Globalização. Oeiras: Celta, 1999. 